ISBN 978-93-84422-85-1

11th International Conference on Chemical, Agricultural, Biological and Environmental Sciences

(CABES-2018)

April 17-18, 2018 Kyoto (Japan)

\title{
Effect of Synthesis Method and Amount of Silver on Physicochemical Properties and Photocatalytic Activity of Ag Doped $\mathrm{TiO}_{2}$ Nanoparticles
}

\author{
Adilah Sirivallop $^{1,2}$, Siriluk Chiarakorn ${ }^{3}$ and Thanita Areerob ${ }^{4}$ \\ ${ }^{1}$ Division of Environmental Technology, The Join Graduate School of Energy and Environment, King \\ Mongkut's University of Technology Thonburi, Thailand \\ ${ }^{2}$ Center of Excellence on Energy Technology and Environment, PERDO, Bangkok, Thailand \\ ${ }^{3}$ Division of Environmental Technology, School of Energy, Environment and Materials, King Mongkut's \\ University of Technology Thonburi, Bangkok, Thailand \\ ${ }^{4}$ Division of Technology and Environment, Prince of Songkla University, Phuket Campus, Phuket, Thailand

\begin{abstract}
Ag}$ doped $\mathrm{TiO}_{2}$ (AgT) nanoparticles have been synthesized by solvothermal method (S) and impregnation method (I) with different amount of silver dopant. In order to study the effect of synthesis method and amount of silver on physical and chemical properties of AgT nanoparticles, X-ray diffraction ( $Q X R D)$, field emission scanning electron microscopy (FESEM) with energy dispersive X-ray spectroscopy (EDS) and UVvisible absorption spectrophotometer (UV-vis) were used to characterize the obtained nanoparticles. The results showed that solvothermal method provided smaller crystallite size, higher surface area and lower band gap energy of photo catalyst than that of impregnation method. The photocatalytic efficiency was evaluated by photo degradation of methylene blue under LED light irradiation. The 10\%AgT synthesized from solvothermal method exhibited the highest photocatalytic efficiency (96.59\%) due to its great physicochemical properties of $\mathrm{TiO}_{2}$ such as small crystallite size, anatase form, high surface area, low band gap energy and the synergistic effect of Ag and $\mathrm{TiO}_{2}$.
\end{abstract}

Keywords: photocatalysis, Ag doping, titaniumdioxide, solvothermal, crystallinity

\section{Introduction}

Photocatalyst is one of smart materials that has received a great attention due to their wide applications for air purification [1, 2], water treatment [3], bacterial removal [4, 5] and other applications in environmental cleaning [6-8]. The fundamental process of photocatalysis is carried out by light irradiation through the semiconductor. Among semiconductors, titanium dioxide $\left(\mathrm{TiO}_{2}\right)$ is the most widely used. This is because $\mathrm{TiO}_{2}$ exhibits high photosensitivity and strong photocatalytic reaction with non-toxic nature, low cost, and environmental friendly $[9,10]$.

Nevertheless, the photocatalysis of $\mathrm{TiO}_{2}$ is limited by its large band gap energy of $\mathrm{TiO}_{2}($ about $3.2 \mathrm{eV}$ ). Accordingly, it is active only under UV light irradiation and rapid recombination between electron-hole pairs of $\mathrm{TiO}_{2}$ can be occurred. These limits cause low photocatalytic reactivity of $\mathrm{TiO}_{2}$ when it is applied under visible light [11].

Silver (Ag) metal doping on $\mathrm{TiO}_{2}$ has been recommended in many researches [12-14] for improving the photoactivity of $\mathrm{TiO}_{2}$ [5]. Ag deposited on $\mathrm{TiO}_{2}$ has positive effects on the photoactivity in terms of narrowing band gap energy of $\mathrm{TiO}_{2}$ by the surface plasmon resonance of $\mathrm{Ag}$, resulting in extend range of the visible light absorption [15] and prevention of recombination between electron-hole pair [10]. In this work, we studied the 
effect of two different synthesis methods (solvothermal and impregnation) and Ag loading on the photocatalytic activity of doped $\mathrm{TiO}_{2}$. Moreover, the crystal structure, optical properties and morphology of Ag doped $\mathrm{TiO}_{2}$ nanoparticles were examined. The photocatalytic activities of $\mathrm{Ag}$ doped $\mathrm{TiO}_{2}$ were examined by the degradation of methylene blue (MB) under visible light illumination compared with bare $\mathrm{TiO}_{2}$.

\section{Materials and Methods}

\subsection{Materials}

All chemical reagents used for the synthesis of the modified $\mathrm{TiO}_{2}$ nanoparticles were analytical grade without further purification. Titanium (IV) butoxide $\left(\mathrm{Ti}\left(\mathrm{OC}_{4} \mathrm{H}_{9}\right)_{4}, \geqslant 97 \%\right)$ was purchased from Fluka. Silver nitrate $\left(\mathrm{AgNO}_{3}, 99 \%\right)$, Ethanol $\left(\mathrm{C}_{2} \mathrm{H}_{5} \mathrm{OH}, 99.8 \%\right)$ and Nitric acid $\left(\mathrm{HNO}_{3}, 65 \%\right)$ were purchased from Merck. Commercial $\mathrm{TiO}_{2}$ with anatase form was purchased from chemical village co.,ltd., China. Methylene blue (MB, $\geqslant 96 \%$ ) was purchased from Unilab and used for photocatalytic experiment. Deionizer water was used in all experiments.

\subsection{Ag Doped $\mathrm{Tio}_{2}$ Preparation by Solvothermal Method}

$\mathrm{Ag}$ doped $\mathrm{TiO}_{2}(\mathrm{AgT})$ were prepared by solvothermal method. Firstly, Ti solution was prepared by dissolving $34 \mathrm{~mL}$ of $\mathrm{Ti}\left(\mathrm{OC}_{4} \mathrm{H}_{9}\right)_{4}$ in $90 \mathrm{~mL}$ of ethanol. After stirring for $15 \mathrm{~min}, 1.26 \mathrm{~mL}$ of $\mathrm{HNO} 3$ and $3.6 \mathrm{~mL}$ of distilled water were dropped into Ti solution, respectively. Secondly, Ag solution (5, 10 and 15\% mol of Ag) was prepared by dissolving in $20 \mathrm{~mL}$ of ethanol. Finally, Ag solution was slowly added into Ti solution with magnetic stirring for $3 \mathrm{~h}$. The obtained $\mathrm{AgT}$ sol was transferred into a teflon-lined stainless steel autoclave during $3 \mathrm{~h}$ at $250{ }^{\circ} \mathrm{C}$. After washing by ethanol and distilled water, the obtained precipitate was dried at $100{ }^{\circ} \mathrm{C}$ for $24 \mathrm{~h}$ and calcined at $550{ }^{\circ} \mathrm{C}$ for $3 \mathrm{~h}$. The as-synthesized $\mathrm{AgT}$ nanoparticles were obtained.

\subsection{Ag Doped $\mathrm{Tio}_{2}$ Preparation by Impregnation Method}

Firstly, $8 \mathrm{~g}$ of commercial $\mathrm{TiO}_{2}$ anatase was dissolved in $100 \mathrm{~mL}$ of distilled water and then an appropriate amount of dopant was added to Ti suspension under stirring. Next, the slurry was stirred continuously for $3 \mathrm{~h}$ before drying in an air oven at $110^{\circ} \mathrm{C}$ for $24 \mathrm{~h}$. Finally, the dried solids were crushed to fine powder with an agate mortar before calcination at $550^{\circ} \mathrm{C}$ for $3 \mathrm{~h}$. The sample ID of all the obtained nanoparticles synthesized by solvothermal method and impregnation method were given in Table I.

\subsection{Characterization}

The structural and morphological characterizations of all synthesized photocatalysts were carried out by the quantitative X-ray diffraction (QXRD) using a $\mathrm{Cu} \mathrm{K} \alpha$ radiation source $(\lambda=1.54 \AA$ ) operated at $50 \mathrm{kV}$ and 50 $\mathrm{mA}$, field emission scanning electron microscope (FESEM) equipped with an energy dispersive X-ray (EDX) analyzer operating at $15 \mathrm{kv}$. The absorption edge wavelengths were recorded by UV-vis Near Infrared Spectrometer within the range 300-700 nm (Perkin Elmer, Lambda 950) and the surface area of the nanoparticles was analyzed by BET method.

\subsection{Photoactivity Test}

The photocatalytic activity of synthesized nanoparticles was evaluated by the decolorization of methylene blue (MB) solution under LED light irradiation. The experiment was carried out in a closed wooden box with dimensions of $30 \times 40 \times 60 \mathrm{~nm}$. A LED lamp (16 W, General Electric) was equipped at the top center of a closed wooden box and parallel with a photoreaction in a beaker with distance of $15 \mathrm{~cm}$ from the bottom of a beaker. The experiment was divided into two steps. Firstly, $1 \mathrm{~g}$ of the synthesized $\mathrm{TiO}_{2}$ nanoparticles dispersed in 100 $\mathrm{mL}$ of 1x10-5 $\mathrm{M}$ of $\mathrm{MB}$ solution was kept under dark condition for $3 \mathrm{~h}$ in order to obtain the adsorptiondesorption equilibrium between catalyst and MB solution. Secondly, the reactor with new MB solution was then irradiated with LED light lamp for $6 \mathrm{~h}$. Every $30 \mathrm{~min}, 5 \mathrm{~mL}$ of $\mathrm{MB}$ solution was taken out and centrifuged at 6,000 rpm for $10 \mathrm{~min}$ to separate the nanoparticles. The decolorization of the centrifuged $\mathrm{MB}$ solution was 
measured by UV-vis spectrophotometry at the maximum wavelength of $664 \mathrm{~nm}$. The degradation efficiency of MB was calculated by using formula (1).

$$
\text { Degradation efficiency }(\%)=\left(\frac{\mathrm{C}_{0}-\mathrm{C}_{\mathrm{t}}}{\mathrm{C}_{0}}\right) \times 100
$$

Where $\mathrm{C}_{0}$ is initial concentration of $\mathrm{MB}$ and $\mathrm{C}_{\mathrm{t}}$ is a concentration of $\mathrm{MB}$ at a measuring time $(\mathrm{t})$

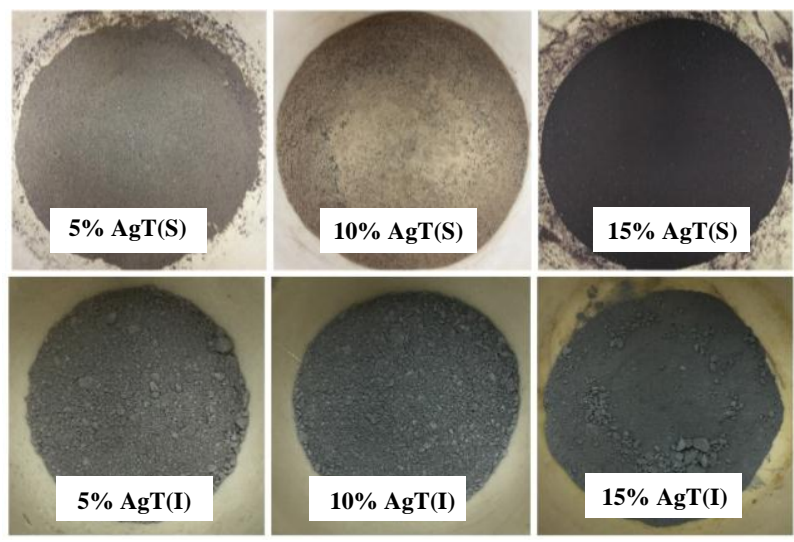

Fig. 1: The Obtained $\operatorname{AgT}(\mathrm{S})$ and $\mathrm{AgT}(\mathrm{I})$ nanoparticles via different synthesis method and different $\mathrm{Ag}$ loading

TABLE I: Physical properties of Ag doped $\mathrm{TiO}_{2}$ nanoparticles

\begin{tabular}{|c|c|c|c|}
\hline Sample ID $^{\mathrm{a}}$ & Crystal phase $^{\mathrm{b}}(\%)$ & Band gap (eV) & Crystal size $(\mathrm{nm})^{\mathrm{T}}$ \\
\hline $\mathrm{T}(\mathrm{S})$ & $\mathrm{A}: 100$ & 3.35 & 28.36 \\
\hline $\mathrm{T}(\mathrm{I})$ & $\mathrm{A}: 100$ & 3.40 & 39.76 \\
\hline $5 \% \mathrm{AgT}(\mathrm{S})$ & $\mathrm{A}: 100$ & 2.90 & 24.66 \\
\hline $10 \% \mathrm{AgT}(\mathrm{S})$ & $\mathrm{A}: 100$ & 2.50 & 20.55 \\
\hline $15 \% \mathrm{AgT}(\mathrm{S})$ & $\mathrm{A}: 54 ; \mathrm{R}: 46$ & 2.26 & 21.27 \\
\hline $5 \% \mathrm{AgT}(\mathrm{I})$ & $\mathrm{A}: 100$ & 3.26 & 55.98 \\
\hline $10 \% \mathrm{AgT}(\mathrm{I})$ & $\mathrm{A}: 100$ & 3.26 & 54.54 \\
\hline $15 \% \mathrm{AgT}(\mathrm{I})$ & $\mathrm{A}: 100$ & 3.20 & 51.26 \\
\hline
\end{tabular}

${ }^{\mathrm{a}} \mathrm{T}, \mathrm{S}$, and I denote titaniumdioxide, solvothermal method and impregnation method, respectively.

${ }^{\mathrm{b}} \mathrm{A}$ and $\mathrm{R}$ denote anatase and rutile phase, respectively.

\section{Results and Discussion}

\subsection{Physical and Structural Properties}

$\mathrm{Ag}$ doped $\mathrm{TiO}_{2}(\mathrm{AgT})$ nanoparticles with different amounts of $\mathrm{Ag}$ dopant (5\%, 10\% and 15\% mol) were prepared by solvothermal method and impregnation method. The obtained nanoparticles of AgT were shown in Fig. 1. The results showed that the obtained $\mathrm{AgT}$ nanoparticles from solvothermal $(\operatorname{AgT}(\mathrm{S}))$ and impregnation methods (AgT(I)) had different colors varying from pale gray (low Ag loading) to dark brown (high $\mathrm{Ag}$ loading). The different color of $\mathrm{Ag}$ doped $\mathrm{TiO}_{2}$ nanoparticles might be explained by the partial reduction of $\mathrm{Ag}$ from $\mathrm{Ag}^{+}$to $\mathrm{Ag}^{0}$ during synthesis process [13]. As a result, the reduction of $\mathrm{Ag}$ caused the formation of $\mathrm{Ag}_{2} \mathrm{O}$ and $\mathrm{Ag}^{0}$ deposited on $\mathrm{TiO}_{2}$ nanoparticles.

\subsection{XRD Analysis}

To investigate the change of the $\mathrm{TiO}_{2}$ crystallinity affected by different Ag loading, the quantitative XRD patterns of as-synthesized nanoparticles were examined in the range of $20-80^{\circ}$ as shown in Fig. 2 . The results showed that all AgT had observable anatase phase at $25^{\circ}(101)$, except for $15 \% \operatorname{AgT}(\mathrm{S})$ small rutile phase was observed at $27^{\circ}(110)$. The phase transformation to rutile could occur at the higher temperature $\left(>550{ }^{\circ} \mathrm{C}\right)$ when using the excessive amount of $\mathrm{Ag}$ metal in the solvothermal process [16-17]. $\mathrm{AgT}(\mathrm{S})$ and $\mathrm{AgT}(\mathrm{I})$ catalysts had additional peaks at $2 \theta$ value of $44.3^{\circ}$ (111) which was attributed to the crystal planes of metallic silver. The content of Ag dopant and synthesis method have significant effects on the crystalline structure of doped $\mathrm{TiO}_{2}$. 
The crystallite size of nanoparticles can be estimated from the strongest peak of anatase following the Scherrer's equation. The XRD peaks of samples synthesized by solvothermal method were broader than the catalyst synthesized by impregnation method. This indicated that solvothermal gave smaller crystallite size than impregnation. This is in agreement with the averaged grain sizes of anatase as presented in Table I.

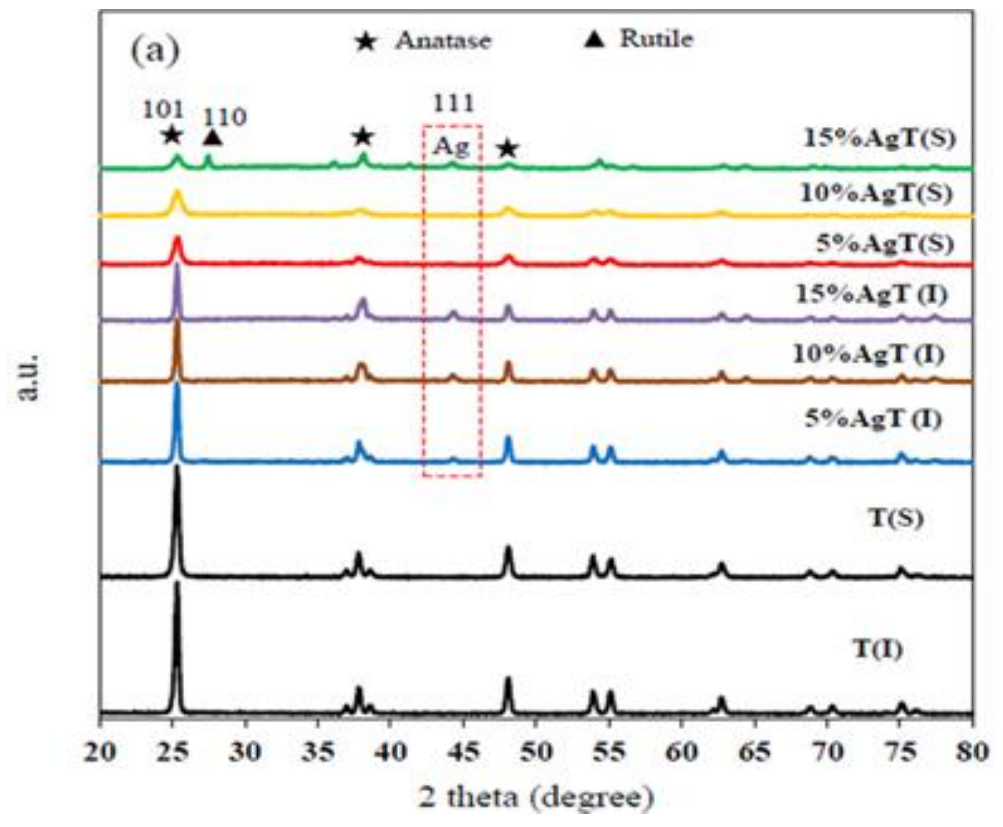

Fig. 2: XRD patterns of $\mathrm{AgT}(\mathrm{S})$ and $\mathrm{AgT}(\mathrm{I})$ nanoparticles via different amount of $\mathrm{Ag}$ loading $(5 \%, 10 \%$ and $15 \%$ mol)

\subsection{SEM Analysis}

FESEM images illustrated in Fig. 3 clearly show that AgT(I) nanoparticles have uniform in spherical shape, particle size, and particles dispersion. The addition of Ag had no significant change in the morphology of AgT nanoparticles compared to bare $\mathrm{TiO}_{2}$. The average particle sizes of AgT(I) from the FESEM images were approximately $100 \mathrm{~nm}$, larger than that of $\operatorname{AgT}(\mathrm{S})$, which was only $50 \mathrm{~nm}$. This is a similar trend with the crystallite sizes determined from the XRD patterns. The images of $\operatorname{AgT}(\mathrm{S})$ in Fig. 3(e-h) indicated the aggregation of a large number of small spherical particles. The aggregation is caused by the suppression of grain growth under high temperature and pressure inside an autoclave. As a result, small sized particles were formed and aggregated rapidly $[18,19]$. The present of $\mathrm{Ag}$ on the $\mathrm{TiO}_{2}$ surface was confirmed by EDX analysis as shown in Table II.

\subsection{Optical Properties}

The UV-vis absorption spectra of AgT and T nanoparticles were collected in the wavelength range of 200$800 \mathrm{~nm}$. The calculated band-gap energy (Eg) values are shown in Table I. It reveals that Eg values of AgT(S) are dramatically decreased compared to bare T from 3.35 to $2.26 \mathrm{eV}$, whereas the Eg values of AgT(I) are slightly decreased from 3.40 to $3.20 \mathrm{eV}$, upon doping of Ag. The reduction of band-gap energy attributed to the surface plasmon resonance of $\mathrm{Ag}$ in the crystal structure phase $[13,20]$, which extended the light absorption to longer wavelengths. Thus, we can conclude that the deposition of $\mathrm{Ag}$ on $\mathrm{TiO}_{2}$ successfully reduced the band gap energy, extended the light absorption to visible region $[14,15]$.

\subsection{Photocatalytic Performance}

The photocatalytic activity of pure $\mathrm{T}$ and $\mathrm{AgT}$ nanoparticles were evaluated by the photodegradation of $\mathrm{MB}$ solution under white LED light irradiation. The MB photodegradation of AgT nanoparticles were shown in Fig. 4. The result showed that the photocatalytic activities of all AgT nanoparticles under LED light were improved when compared to bare $\mathrm{T}$ due to their higher visible light absorption of $\mathrm{TiO}_{2}$ upon $\mathrm{Ag}$ doping. The efficiency of the catalysts for MB photodegradation followed the order: $\operatorname{AgT}(\mathrm{S})(92-96 \%)>\operatorname{AgT}(\mathrm{I})(73-83 \%)>\mathrm{T}(\mathrm{S})(57 \%)>$ 
$\mathrm{T}(\mathrm{I})(43 \%)$. The photocatalytic activity of nanoparticles synthesized by solvothermal method or AgT(S) was higher than nanoparticles synthesized by impregnation method (AgT(I)) due to their lower band gap energy and smaller crystallite size which result in the higher specific surface area. Among the synthesized photocatalysts, $10 \% \mathrm{AgT}(\mathrm{S})$ had the highest photocatalytic activity followed by $15 \% \mathrm{AgT}(\mathrm{S})$. The excess amount of $\mathrm{Ag}(15 \% \mathrm{~mol})$ could prevent the light absorption of $\mathrm{TiO}_{2}$ resulting in the interrupt photoactivity. Hence, these phenomena confirm that the solvothermal synthesis and the optimal of Ag amount significant effect on the enhancement photocatalytic performance under visible light irradiation.

TABLE II: Composition of AgT nanoparticles according to EDX Analysis

\begin{tabular}{|l|c|c|c|}
\hline \multicolumn{1}{|c|}{ Samples } & Ti (\%wt) & O (\%wt) & Ag (\%wt) \\
\hline $5 \% \operatorname{AgT}(\mathrm{S})$ & 32.39 & 5.73 & 1.77 \\
\hline $10 \% \operatorname{AgT}(\mathrm{S})$ & 57.51 & 37.15 & 5.34 \\
\hline $15 \% \operatorname{AgT}(\mathrm{S})$ & 51.24 & 41.52 & 7.25 \\
\hline $5 \% \operatorname{AgT}(\mathrm{I})$ & 70.51 & 28.59 & 0.82 \\
\hline $10 \% \operatorname{AgT}(\mathrm{I})$ & 67.90 & 31.28 & 0.90 \\
\hline $15 \% \operatorname{AgT}(\mathrm{I})$ & 71.16 & 27.25 & 1.59 \\
\hline
\end{tabular}
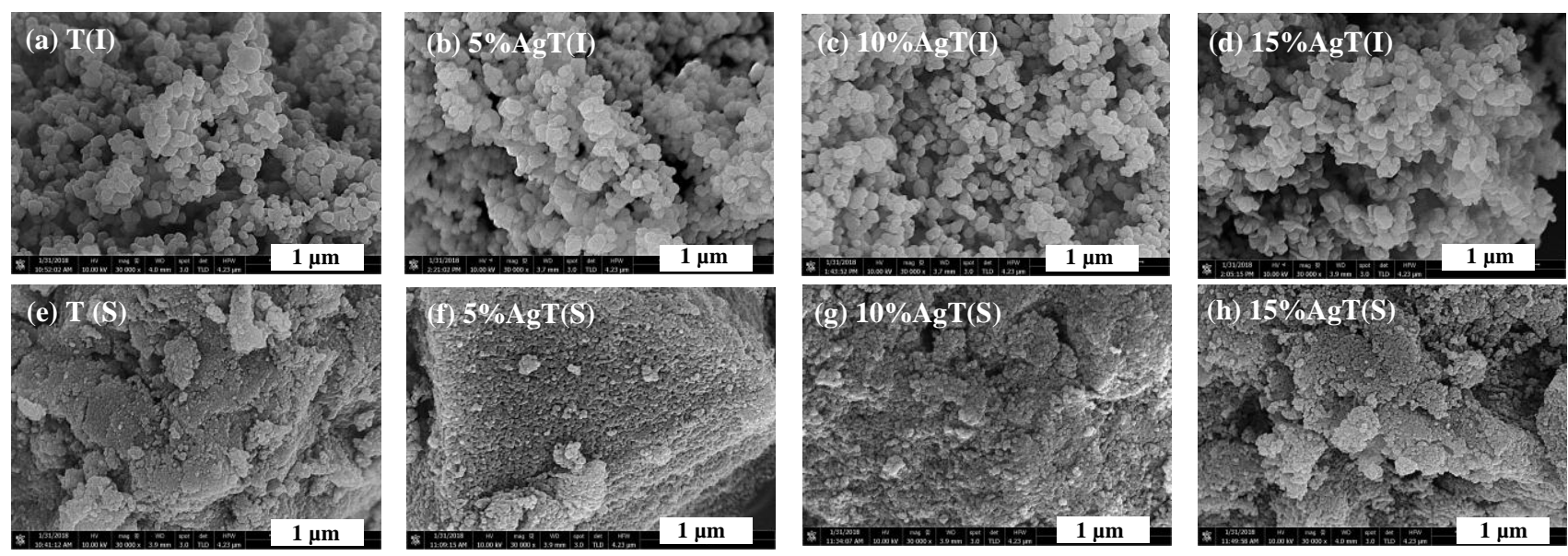

Fig.3: FESEM Images of the obtained T and AgT nanoparticles synthesized by Impregnation method and Solvothermal method

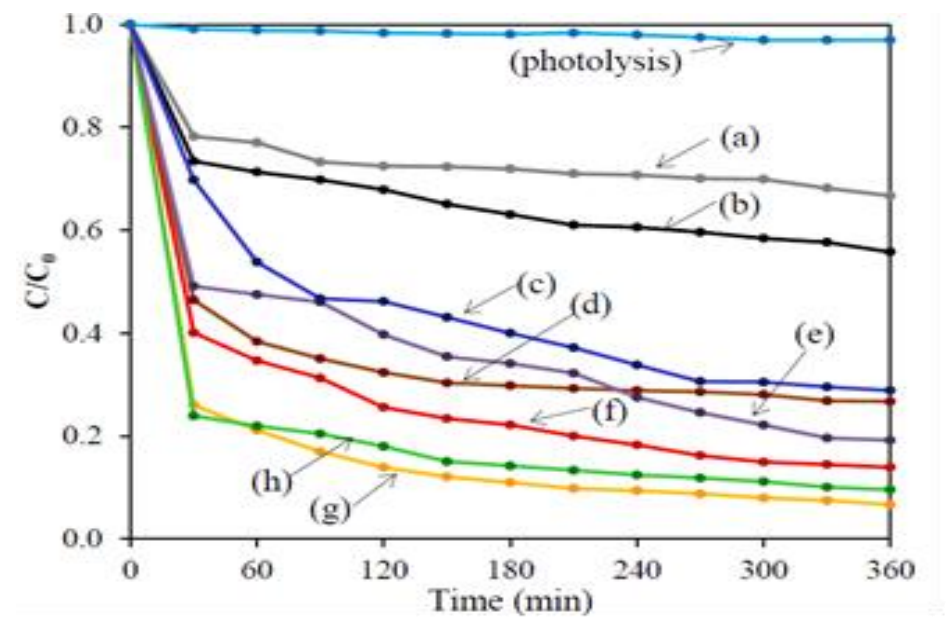

Fig. 4: The MB photodegradation under visible light irradiation by (a) T(I), (b) T(S), (c) 5\% AgT(I), (d) $10 \% \mathrm{AgT}(\mathrm{I}),(\mathrm{e}) 15 \% \mathrm{AgT}(\mathrm{I}),(\mathrm{f}) 5 \% \mathrm{AgT}(\mathrm{S}),(\mathrm{g}) 10 \% \mathrm{AgT}(\mathrm{S})$ and $(\mathrm{h}) 15 \% \mathrm{AgT}(\mathrm{S})$ 


\section{Conclusion}

In summary, the synthesis of $\mathrm{Ag}$ doped $\mathrm{TiO}_{2}$ photocatalysts with different amount of $\mathrm{Ag}(5 \%, 10 \%$ and $15 \%$ mol) using solvothermal method $(\operatorname{AgT}(\mathrm{S}))$ and impregnation method $(\operatorname{AgT}(\mathrm{I}))$ were carried out. The results show that the synthesis method and the amount of Ag play an important role in photocatalytic reactivity of $\mathrm{TiO}_{2}$. AgT synthesized by solvothermal method with $10 \%$ Ag loading is a promising photocatalyst due to its small crystalline size, uniformly particles dispersion and large specific area. Overall photocatalytic performance of $\mathrm{AgT}$ under visible light irradiation can be improved by the synergistic effect between $\mathrm{Ag}$ and $\mathrm{TiO}_{2}$. $\mathrm{Ag}$ doping on $\mathrm{TiO}_{2}$ can facilitate the photoreaction by reducing band gap energy, extending wavelength absorption to visible light region and minimizing recombination of electron-hole. The highest MB photodegradation by $10 \% \mathrm{AgT}(\mathrm{S})$ was increased to $96 \%$.

\section{Acknowledgment}

The authors would like to thank the Joint Graduate School of Energy and Environment, King Mongkut's University of Technology Thonburi, Center of Excellence on Energy Technology and Environment, PERDO, Bangkok, Thailand, and the Pectcha Pra Jom Klao Doctural Degree Research Scholarship from King Mongkut's University of Technology Thonburi for financial support and necessary facility providing.

\section{References}

[1] M. Guarino, A. Costa, and M. Porro, "Photocatalytic $\mathrm{TiO}_{2}$ coating-to reduce ammonia and greenhouse gases concentration and emission from animal husbandries," Bioresource Technology, vol. 99, pp. 2650-2658, 2008.

https://doi.org/10.1016/j.biortech.2007.04.025

[2] Y. Boyjoo, H. Sun, J. Liu, V. K. Pareek, and S. Wang, "A review on photocatalysis for air treatment: From catalyst development to reactor design," Chemical Engineering Journal, vol. 310, Part 2, pp. 537-559, 2017.

https://doi.org/10.1016/j.cej.2016.06.090

[3] Q. Chen, Y. Zhang, D. Zhang, and $\mathrm{Y}$. Yang, "Ag and $\mathrm{N}$ co-doped $\mathrm{TiO}_{2}$ nanostructured photocatalyst for printing and dyeing wastewater," Journal of Water Process Engineering, vol. 16, pp. 14-20, 2017.

https://doi.org/10.1016/j.jwpe.2016.11.007

[4] C. Thunyasirinon, "Enhancement of Air Filter with $\mathrm{TiO}_{2}$ Photocatalysis for Mycobacterium Tuberculosis Removal," 2015.

[5] X. Hou, H. Ma, F. Liu, J. Deng, Y. Ai, X. Zhao, D. Mao, D. Li, and B. Liao, "Synthesis of Ag ion-implanted $\mathrm{TiO}_{2}$ thin films for antibacterial application and photocatalytic performance," Journal of Hazardous Materials, vol. 299, pp. 5966, 2015.

https://doi.org/10.1016/j.jhazmat.2015.05.014

[6] L. Tang G, "Converting Volatile Organic Compounds to $\mathrm{CO}_{2}$ and Water " American Journal of Chemical Engineering, vol. 4, pp. 62-67, 2016.

https://doi.org/10.11648/j.ajche.20160402.16

[7] M. R. Hoffmann, S. T. Martin, W. Choi, and D. W. Bahnemann, "Environmental applications of semiconductor photocatalysis," Chem vol. 95, pp. 69-96, 1995.

https://doi.org/10.1021/cr00033a004

[8] A. Costa, G. L. Chiarello, E. Selli, and M. Guarino, "Effects of $\mathrm{TiO}_{2}$ based photocatalytic paint on concentrations and emissions of pollutants and on animal performance in a swine weaning unit," Journal of Environmental Management, vol. 96, pp. 86-90, 2012.

https://doi.org/10.1016/j.jenvman.2011.08.025 
[9] F. He, F. Ma, T. Li, and G. Li, "Solvothermal synthesis of $\mathrm{N}$-doped $\mathrm{TiO}_{2}$ nanoparticles using different nitrogen sources, and their photocatalytic activity for degradation of benzene," Chinese Journal of Catalysis, vol. 34, pp. 22632270, 2013.

https://doi.org/10.1016/S1872-2067(12)60722-0

[10] M. Pelaez, N. T. Nolan, S. C. Pillai, M. K. Seery, P. Falaras, A. G. Kontos, P. S. M. Dunlop, J. W. J. Hamilton, J. A. Byrne, K. O'Shea, M. H. Entezari, and D. D. Dionysiou, "A review on the visible light active titanium dioxide photocatalysts for environmental applications," Applied Catalysis B: Environmental, vol. 125, pp. 331-349, 2012. https://doi.org/10.1016/j.apcatb.2012.05.036

[11] X. F. Lei, X. X. Xue, and H. Yang, "Preparation and characterization of Ag-doped $\mathrm{TiO}_{2}$ nanomaterials and their photocatalytic reduction of Cr(VI) under visible light," Applied Surface Science, vol. 321, pp. 396-403, 2014. https://doi.org/10.1016/j.apsusc.2014.10.045

[12] D. Guitoume, S. Achour, N. Sobti, M. Boudissa, N. Souami, and Y. Messaoudi, "Structural, optical and photoelectrochemical properties of $\mathrm{TiO}_{2}$ films decorated with plasmonic silver nanoparticles," Optik - International Journal for Light and Electron Optics, vol. 154, pp. 182-191, 2018.

[13] E. Albiter, M. A. Valenzuela, S. Alfaro, G. Valverde-Aguilar, and F. M. Martínez-Pallares, "Photocatalytic deposition of Ag nanoparticles on $\mathrm{TiO}_{2}$ : Metal precursor effect on the structural and photoactivity properties," Journal of Saudi Chemical Society, vol. 19, pp. 563-573, 2015.

https://doi.org/10.1016/j.jscs.2015.05.009

[14] X. G. Hou, M. D. Huang, X. L. Wu, and A. D. Liu, "Preparation and studies of photocatalytic silver-loaded TiO2 films by hybrid sol-gel method," Chemical Engineering Journal, vol. 146, pp. 42-48, 2009.

https://doi.org/10.1016/j.cej.2008.05.041

[15] H. Zhang, G. Wang, D. Chen, X. Lv, and J. Li, "Tuning photoelectrochemical performances of Ag-TiO nanocomposites via reduction/oxidation of Ag," Chemistry of Materials, vol. 20, pp. 6543-6549, 2008. https://doi.org/10.1021/cm801796q

[16] R. Singh and S. Dutta, "Synthesis and characterization of solar photoactive $\mathrm{TiO}_{2}$ nanoparticles with enhanced structural and optical properties," Advanced Powder Technology, vol. 29, pp. 211-219, 2018.

https://doi.org/10.1016/j.apt.2017.11.005

[17] J. García-Serrano, E. Gómez-Hernández, M. Ocampo-Fernández, and U. Pal, "Effect of Ag doping on the crystallization and phase transition of TiO2 nanoparticles," Current Applied Physics, vol. 9, pp. 1097-1105, 2009. https://doi.org/10.1016/j.cap.2008.12.008

[18] S. Saha, J. M. Wang, and A. Pal, "Nano silver impregnation on commercial $\mathrm{TiO}_{2}$ and a comparative photocatalytic account to degrade malachite green," Separation and Purification Technology, vol. 89, pp. 147-159, 2012. https://doi.org/10.1016/j.seppur.2012.01.012

[19] B. Yu, K. M. Leung, Q. Guo, W. Ming Lau, and J. Yang, "Synthesis of Ag-TiO 2 composite nano thin film for antimicrobial application," vol. 22, 2011.

[20] J. Tae Park, C. Soo Lee, C. Hun Park, and J. Hak Kim, "Preparation of TiO2/Ag binary nanocomposite as highactivity visible-light-driven photocatalyst via graft polymerization," Chemical Physics Letters, vol. 685, pp. 119-126, 2017.

https://doi.org/10.1016/j.cplett.2017.07.054 